\title{
Fatores sociodemográficos associados ao consumo de cálcio em crianças de 6 a 12 meses de vida
}

\author{
Mariane Alves Silva, Marcela Martins Soares, Poliana Cristina de Almeida Fonsêca, Sarah \\ Aparecida Vieira, Juliana Farias de Novaes, Sylvia do Carmo Castro Franceschini
}

\begin{abstract}
Resumo
O cálcio é considerado um nutriente indispensável para o crescimento e desenvolvimento ósseo, além de participar das funções biológicas do organismo. Estudos têm mostrado a relação entre o consumo adequado de cálcio na infância com a prevenção de doenças como osteoporose, hipertensão arterial e obesidade na vida adulta, justificando-se a importância da avaliação da ingestão desse nutriente em crianças. Investigar a relação entre fatores sociodemográficos e o consumo de cálcio em crianças a partir da introdução da alimentação complementar. Estudo de coorte, com 226 crianças, realizado no período de 2011 a 2013 no município de Viçosa-MG. Foi aplicado ao responsável um questionário semiestruturado para obtenção de informações referentes à situação sociodemográfica da criança. O consumo alimentar foi avaliado por meio de um recordatório de 24 horas com o responsável pela criança no sexto, nono ou décimo segundo mês de vida. Os dados do consumo alimentar foram avaliados segundo as Dietary Reference Intakes (DRI). Utilizou-se AI (Adequate Intake) como referência para o cálcio. Considerou-se para a classificação econômica o modelo proposto pela Associação Brasileira de Estudos Populacionais (ABEP, 2010), o qual leva em consideração itens de posse do individuo e grau de instrução do chefe da família. Os indivíduos são divididos nas classes: A, B, C, D e E, sendo que a classe econômica A é a que possui uma maior renda familiar. As análises foram realizadas no software Stata versão 10.0. Na análise bivariada dos fatores associados ao consumo de cálcio abaixo da AI, estimou-se a razão de prevalência e intervalo de confiança pela regressão de Poisson com variância robusta, sendo as variáveis com valor de $\mathrm{p}<0,20$ incluídas no modelo múltiplo. A prevalência de consumo de cálcio abaixo da recomendação foi de $27,0 \%$. Observou-se que crianças classificadas na categoria C, D e E (RP: 0,77; IC95\%: 0,64 - 0,91) e do sexo feminino (RP: 0,79; IC95\%: 0,65 - 0,95) apresentaram menor risco de consumo de cálcio abaixo da recomendação. Crianças pertencentes a famílias com mais de 4 pessoas no domicílio (RP: 1,21; IC95\%: 1,001 - 1,46) tiveram uma prevalência $21 \%$ vezes maior do consumo de cálcio abaixo da AI. Encontrou-se uma maior adequação do consumo de cálcio em crianças do sexo feminino e cuja família se encontrava na categoria $\mathrm{C}, \mathrm{D}$ e $\mathrm{E}$. Uma possível explicação se deva ao fato do maior consumo de mingaus e preparações à base de leite nos níveis socioeconômicos inferiores, principalmente nas pequenas refeições, em substituição ao consumo de frutas. Entretanto, as crianças residentes em domicílios com mais que 4 pessoas apresentaram inadequado consumo de cálcio.
\end{abstract}

Descritores: Consumo Alimentar; Alimentação Infantil; Cálcio. 